\title{
La política exterior española en América Latina durante la II Guerra Mundial
}

\author{
Rosa Ma Pardo SANZ
}

En 1939 el destino político de España quedó en manos de los vencedores de la Guerra Civil. Sus proyectos políticos de partida traslucian la euforia del triunfo y un abigarrado nacionalismo que incluía el sueño de regenerar el país en el ámbito interno e internacional. Los primeros responsables de la política exterior -Franco, Jordana y Beigbeder-compartían la esperanza de acabar con la debilidad militar de la nación y elevar su status como potencia. España estaba llamada a desempeñar un papel relevante en el mundo por su historia, por su posición geoestratégica privilegiada y por el servicio rendido a la civilización y al catolicismo con la "Cruzada". El ejemplo de Alemania e Italia, prestas a desafiar el mismo statu quo que había escamoteado a España sus justas reivindicaciones imperialistas, era un acicate más.

En estas elucubraciones el norte de Africa constituia el objetivo por antonomasia, pero América también tenía su lugar. En la mentalidad colectiva, llevaba un siglo constituyendo el recuerdo de un pasado de grandeza; una especie de paraíso perdido sobre el que, supuestamente, España conservaba ciertos poderes y derechos. La literatura regeneracionista se había encargado durante un tercio de siglo de ubicar allá una de las posibles fuentes del renacer nacional a través de la proyección cultural, comercial y política que el país podía ejercer. Los intelectuales de la extrema derecha republicana habían reelaborado aquellas ideas a la luz de una ideología antiliberal, ultracatólica y hasta fascista dibujando para la nación una "misión» de guía político-espiritual en América. $Y$, por último, la propaganda de guerra había contribuido a reforzar la confianza de los mandatarios franquistas en las posibilidades de una nueva proyección ultramarina para la postguerra ${ }^{\text {. }}$

1 Cit. P. Perez y N. Tabanera (Coord.): España/America Latina: Un siglo de politicas culturales. 
La creación de un área de influencia española en América podia ser el complemento ideal de la ansiada expansión africana. Con ello no se estaba inventando nada. La misma aspiración había sido manejada por el Ministerio de Estado en los años veinte y durante la II República. Sin embargo, equivocadamente, en 1939 se pensó que, tras la hazaña de la Guerra Civil, los instrumentos de penetración tradicionales (una política de prestigio cultural, el apoyo de las colonias españolas, la posible influencia política, etc.) iban a ser más eficaces. La clave estaba en rentabilizar el arma ideológica. A juzgar por las actitudes exhibidas durante la Guerra Civil española por algunos sectores de las élites políticas e intelectuales conservadoras, más los grupos católicos latinoamericanos, el modelo político del Nuevo Estado, con su perfecta alquimia de ingredientes conservadores, fascistas y católicos, podía erigirse en la genuina respuesta hispánica al peligro comunista y a las debilidades de la democracia liberal. Bastaría con una política cultural de prestigio en la que todos los productos ofertados fueran teñidos de nacionalcatolicismo, amén de aprovechar la influencia de los españoles residentes allende el mar aplicando los nuevos modelos de organización y encuadramiento fascistas.

Los errores de cálculo implícitos en este diseño inicial tan optimista eran múltiples. El punto de partida era una percepción nada ajustada de la posición real de España en el sistema internacional y del papel que podía desempeñar en él. En el caso concreto de las posibilidades en América, el error derivaba de una lectura equivocada de las repercusiones de la Guerra Civil sobre las relaciones con el área. Ciertamente, durante la contienda algunos gobiernos habían adoptado actitudes cordiales y tolerantes con las autoridades de Burgos y con sus representantes en ultramar; habia habido guiños filofranquistas de ciertos sectores de las sociedades latinoamericanas y la movilización de las colonias de españoles nacionalistas había sido significativa ${ }^{2}$. Sin embargo, lo decisivo iban a ser otros elementos infravalorados por Madrid. En primer lugar, la antipatía de la opinión pública continental hacia el Nuevo Estado había sido mayoritaria,

Madrid, 1993; M. Huguet, A. Niño y P. Pérez Herrero (Coords.): La formación de la imagen de América Latina en España. 1898-1989. Madrid, 1992; J. C. MAINER: “Un capitulo regeneracionista: el hispanoamericanismo (1892-1923)" en Ideologia y sociedad en la España contemporánea. Madrid, 1977, pp. 149-203; I. SEPULVEDA: Comunidad cultural e Hispanoamericanismo. 1885-1936, Madrid, 1994; E. GonzÁlez y F. LIMÓN: La Hispanidad como instrumento de combate. Raza e Imperio en la Prensa franquista durante la guerra civil española. Madrid, 1988; L. DelgaDo: Imperio de papel. Acción Cultural y Politica Exterior durante el Primer Franquismo. Madrid, 1992.

2 R. PARDO: "Hispanoamérica en la política nacionalista, 1936-9", en Espacio, Tiempo y Forma, S.V, T.5 (1992), pp. 211-38. 
poniendo en evidencia la derrota del bando franquista en el ámbito propagandístico. Por otra parte, desde Madrid se juzgó que la conservadora coyuntura política latinoamericana de 1936-9 había de ser una situación estable, cuando muchos paises iban a evolucionar en un sentido democrático, contrario a los intereses de Madrid, por la movilización ideológica que la II Guerra Mundial iba a promover. Por último, si las relaciones con Madrid siempre habian sido un tema secundario para las cancillerias latinoamericanas, la progresión del ascendiente de los Estados Unidos iba a desplazar a cualquier potencia extracontinental del hemisferio.

Este último factor fue decisivo. Desde 1933 F.D.Roosevelt habia trabajado para romper el tradicional aislacionismo norteamericano. La nación estaba lista para su engrandecimiento internacional y lo más sencillo era comenzar haciendo efectivo el liderazgo que podía ejercer sobre el continente americano. Esa tendencia hegemónica se revistió de un proyecto de coordinación interamericana consistente en crear un bloque diplomático continental -alternativo o complementario a la S.D.N.- de voluntad neutralista y pacifica. Un mecanismo para preservar a América del contagio de la crisis europea merced al diseño de instrumentos con que solventar las disputas interestatales y asegurar la capacidad de respuesta ante cualquier amenaza extracontinental. Los primeros pasos se dieron en las Conferencias Panamericanas de 1936 (Buenos Aires) o 1938 (Lima) y, aunque su efectiva realización no tuvo lugar hasta bien entrada la II Guerra Mundial, ya en abril de 1939 se habian esbozado programas multilaterales de cooperación política, económica, militar y cultural ${ }^{3}$.

La otra cara de semejantes despliegues era la pretensión de obstaculizar la penetración europea en América. En el caso inglés, la competencia se reducía al ámbito comercial y tenía su más clara incidencia en el mercado argentino. Con Alemania, a la rivalidad económica se añadia la amenaza militar y política. Los gobiernos alemán e italiano disponían de filiales de sus partidos únicos y contaban con medios de prensa y propaganda que podian emplear como instrumentos de subversión internacional. De

3 Cif. R. Dallek, Franklin D. Roosevelt and American Foreign Policy, 1932-1945. Oxford, 1979 y The American Style of Foreign Policy. Oxford, 1983, pp. 118-20; I. GELLmAN, Good Neighbour Diplomacy U.S. Policies in Latin America, 1933-1945. Baltimore, 1979; R.A. HUMPHREYS: Latin America and the Second World War. Vol.l. 1939-1942. Athlone, 1981; R.F.SMITH: The United States and the Latin American Sphere of Influence. Era of Good Neighbors. Cold Warriors and Hairshirts, 1930-1982. (Vol. II), Malabar, 1983, p. 34; J.M. ESPINOSA: Inter-American Beginnings of U.S. Cultural Diplomacy, 1936-1948. Washington, 1976, pp. 120-142 y C. A. THOMSON \& W.H. LAVES: Cultural Relations and U.S. Foreign Policy. Bloomington, 1963, pp. 30-43. 
hecho habian usado la Guerra Civil española para alentar la influencia autoritaria y fascista en el continente americano ${ }^{4}$. En el fondo, los designios oficiales germanos en América Latina pretendian fortalecer la posición socio-económica de los alemanes en ultramar como herramienta de la pugna comercial, predisponer a la opinión pública americana a favor de sus pretensiones en Europa y, quizás, intentar debilitar a aquellos gobiernos (los EE.UU., por ejemplo) con suficiente poder como para entorpecer la diplomacia nazi en el ámbito europeo. Lo mismo ocurría con Mussolini, que pretendia ir creando una carta diplomática latinoamericana para usarla en su política europea ${ }^{5}$. Sin embargo, el potencial subversivo nazifascista pareció amenazador a los ojos de Washington: el abandono italiano de la S.D.N. habia sido seguido por Guatemala, Honduras y El Salvador; en 1938 el partido Integralista de Brasil y el Movimiento Nacional Socialista (M.N.S.) chileno habian ensayado - sin éxito-golpes de supuesta inspiración totalitaria y, ya en la primavera de 1939, se expandieron rumores acerca de una posible anexión alemana de la Patagonia argentina. Además, la aprensión de que el hemisferio occidental (sobre todo el

4 W.F. KimBalL: "The Juggler': Franklin D.Roosevelt and Anglo-American Competition in Latin America" en G.di TelLA y D.C.WATT: Argentina between the Great Powers, 1939-1946. Oxford, 1990. pp.19-33 y 119-22; D.C.WATt: Succeeding John Bull: America in Britain's Place. Cambridge, 1984; M.GRow: The Good Neighbor Policy and Authoritarianism in Paraguay. United States Economic Expansion and Great Power Rivalry in Latin America during World War II. Lawrence, 1981, pp. 22-35; A.Frye: Nazi Germany and the American Hemisphere, 1933-1941. New Haven \& London,1967, pp. 11-33 y M.Mugnani: Mussolini e l'America latina 1936-1943: un disegno globle?. Tesi di laurea (inédita), Universita degli Studi di Fireze, 1983-84, pp. 74-82.

5 En ningún caso consideró Hitler que la contribución de América Latina al futuro esfuerzo bélico pudiese ser básica, ni se ha logrado documentar que la región constituyera un objetivo de la gran política de "espacio vital» nazi. Otra cosa fue que, en su esfuerzo por retener fuentes teóricas de materias primas, desplegase campañas de propaganda destinadas a estimular la resistencia nacionalista a la penetración norteamericana denunciando la politica de Buena Vecindad (sobre todo desde fines de 1939). También ocurrió que algunos elementos «iluminados" y visionarios del partido nazi pudiesen maquinar, al margen de las embajadas alemanas, conspiraciones y golpes de mano más o menos fantasiosos. O bien que en determinados momentos se llegara a pensar en una estrategia común establecida entre potencias fascistas para fines coyunturales muy concretos: cuando se pensó asociar a algún pais latinoamericano al Pacto Antikomintern, cuando se bosquejaron planes conjuntos para contrarrestar la campaña de propaganda antitotalitaria 0 , posteriormente. cuando desde 1939, se buscó la neutralidad latinoamericana en la Segunda Guerra Mundial. Cif. R.C. NEWTON: "Disorderly Succession: Great Britain, The United States and the 'Nazi Menace'in Argentina, 1938-1947", en G. Tella y D.C. WATT: Op. cit. p.114-5 y 122 y «The German-Argentines between Nazism and Nationalism: The Patagonia Plot of 1939", en International History Review, $\mathrm{n}^{\circ}$ 3. (Jan. 1981), pp.76-77 y 83-92; A. EBEL: Das Dritte Reich und Argentinien. Die diplomatischen Beziehungen unter besonderer Berücksichtigung der Handels-politik (1933-1939). Colonia, Böhlau, 1971, p. 272 y "The German-Argentines between Nazism and Nationalism: The Patagonia Plot of 1939 ", en International History Review, $\mathrm{n}^{\circ}$ 3. (Jan.1981), pp. 76-92 y C. BuChruker:: Nacionalismo y Peronismo. La Argentina en la Crisis ideológica mundial, 1927-1955. Buenos Aires, 1987, p.185. 
Caribe) fuera vulnerable a ataques aéreos o submarinos fue calando en la opinión norteamericana ${ }^{6}$.

Que tales sospechas contenían más elementos de fantasía que de realidad es algo probado hoy, pero desde fines de 1938 la política de Buena Vecindad se convirtió en un apéndice de la política antitotalitaria por la que había optado como línea maestra la diplomacia rooseveltiana. La cooperación hemisférica se intensificó a fin de prevenir focos de inestabilidad que pudieran ser explotados por el Eje para su penetración comercial o política. A un tiempo, se inauguró una operación continental tendente a la vigilancia y control de todas las ideologias sospechosas de erosionar los principios democráticos. Tras las ilegalizaciones precursoras de Vargas en Brasil y de Ubico en Guatemala, en la Conferencia de Lima se aprobó por unanimidad una resolución contra "toda intervención o actividad extranjera" $y$ en varios paises se restringieron legalmente las actividades proselitistas italoalemanas (Argentina, México y Cuba) ${ }^{7}$.

La España de Franco no podía haber elegido peor momento para poner en marcha una política de altos vuelos en América. El frente antifascista salpicó de inmediato al partido de FET-JONS y por extensión al nuevo régimen de Burgos. En abril de 1939 tenían lugar las primeras expulsiones y prohibiciones contra las filiales del partido único español en Cuba y México ${ }^{8}$. A pesar de la prudencia de Jordana, que refrenó las expectativas radicales de Falange Exterior y evitó cualquier concertación con nazis y fascistas, la propaganda antifalangista comenzó a aparecer en la prensa oficial de muchos países entrelazada con las proclamas generales antitotalitarias. Si el ensayo de encuadrar a las colonias españolas bajo la obediencia falangista ya habia causado bastantes problemas durante la Guerra Civil (enfrentamientos internos, estructuras de poder paralelas a

6 F.B. PIKE: Chile and the United States, 1880-1962. The Emergence of Chile's Social Crisis and the Challenge to United States Diplomacy. Notre Dame, 1965, p.206-8; S.E. HILTON "The United States and Argentina in Brazil's Wartime Foreign Policy, 1939-1945" en G. TELLA \& C. WATT: Op. cit., p. 159. El miedo a ataques germanos tuvo como derivacion inmediata un cambio en la planificación militar defensiva americana que por primera vez consideraba probable un ataque alemán sobre el continente (Planes Rainbow): F.A. BAPTISTE: War Cooperation and Conflict: the European Possesions in the Caribbean, 1939-1945. New York, 1988, p. 6 y Cif. J.P. Diggins: L'America, Mussolini e il fascismo. Bari, 1982.

R. Gelman, Op.cit., p. 81 y "Cárdenas a Jordana, 22-6-1939", en AMAE, R-1004/8; K. Grieb: Guatemalan Caudillo. The Regime of Jorge Ubico. Guatemala: 1931-1944. Athens, 1979, pp.249 53; M. Mugnani: Mussolini e l'America..., p. 151-2; el decreto argentino en AMAE, R$1002 / 14$.

8 "Lojendio a Jordana, 5-4-1939" en AMAE, R-1002/14; "López Escobar a Jordana, 23-51939 y 28-5-1939" en AMAE, R-1004/8 y AMAE, R-2449/4; “J.de Cárcer a Jordana, 3-6-1939", en AMAE, R-1003/2; AGA.AE. 8727. 
los diplomáticos, etc.), los incidentes y manifestaciones antifranquistas no iban a cejar desde 1939. El desinflamiento del proselitismo falangista resultó imparable.

Además de que la situación política de muchos países (Chile, Argentina, Uruguay, Venezuela y Ecuador) evolucionó en un sentido democrático, algunos de los dictadores más profranquistas hasta 1938 (Vargas, Batista, Somoza, Ubico...) se sumaron a la política antitotalitaria patrocinada por Washington a cambio de los beneficios (económicos, militares, etc.) que reportaba una relación fluida con los EE.UU. El grueso de la opinión democrática latinoamericana mantenía sus recelos contra el Nuevo Estado: la presencia del exilio republicano era el recordatorio permanente de la tragedia española. Por último, la propia evolución interna del franquismo empañó aún más la imagen del régimen, dada la progresiva mimetización con los modelos totalitarios europeos en vista de la influencia creciente del aparato falangista y de Serrano Súñer.

Durante algunos meses, Jordana procuró ajustar sus objetivos a la capacidad de maniobra real del pais. Se limitó a normalizar en lo posible las relaciones reconstruyendo la red diplomática, a dar los primeros pasos para la creación de una mínima infraestructura propagandística y a tratar de controlar las actividades falangistas. Pero, hasta el verano de 1939 la falta de medios, la rigidez con que se afrontaron las primeras negociaciones (con Chile, Cuba o Panamá), la retracción y división de las colonias españolas y un contexto internacional cada vez menos propicio no permitieron avance alguno. El relevo de Jordana, que significaba la decantación internacional del régimen hacia el bloque fascista europeo, menoscabó aún más la posición española ${ }^{9}$.

Desde agosto de 1939, los presupuestos seguidos por Beigbeder no fueron muy distintos de los de su antecesor; mas, el estallido de la II Guerra Mundial complicó los nexos con el área. A las primeras actividades antifranquista tras del exilio republicano, se sumaron los despliegues de la propaganda bélica antitotalitaria de las potencias democráticas y nuevas restricciones a las actividades extranjeras sospechosas de totalitarismo o quintacolumnismo. Desde principios de 1940, el temor a ser incluidos en las listas negras proclamadas por Londres y la polarización política derivada de la guerra agudizó la desmovilización de los simpatizantes franquistas; sobre

9 Para todo el desarrollo de la politica en la región durante el periodo estudiado, remitimos a R. PARDO SANZ: “Con Franco hacia el imperio". La politica exterior española en América Latina, 1939-45. Madrid. UNED. 1995 (en prensa). 
todo de los grupos falangistas, cuyas filiales (con la excepción de Paraguay y Cuba) se deshicieron o quedaron reducidas a sus cuadros de mando antes del verano de $1940^{10}$. También se mostraron de inmediato las limitaciones de la confianza que Madrid había depositado en las simpatías de los círculos políticos conservadores y católicos latinoamericanos. La derecha de tradición liberal renegó completamente de un régimen cada vez más fascistizado. Los medios católicos, convulsionados por la tensión ideológica del momento, se distanciaron de un régimen que mantenia relaciones tirantes con el Vaticano y que se asemejaba por momentos a los otros totalitarismos condenados por el Papa ${ }^{11}$. En contra de lo creído por Madrid, los únicos sectores latinoamericanos que sintonizaban ideológicamente con el régimen de Franco eran grupos minoritarios de la nueva derecha (imbuida de los modelos fascistas europeos), junto con nacionalistas y reductos católicos integristas y antiliberales. Sectores que, al decantarse por posiciones neutralistas y ambiguas sobre la guerra, levantaron las sospechas de Washington y quedaron - casi siempre - reducidos a la oposición y al aislamiento de sus propios gobiernos y sociedades. Porque ningún gobierno (ni siquiera el argentino) dudó en seguir las directrices panamericanas marcadas por Washington; entre otras razones, porque lo que estaba en juego en la relación con los EE.UU. era, a menudo, el bienestar de muchas economías nacionales.

En el Palacio de Santa Cruz no se supo o no se quiso apreciar la gravedad del impacto de la guerra europea en América ni sus consecuencias para los intereses españoles. Con los esquemas de la Guerra Civil como marco de referencia, se estimó la situación en términos de una conspiración internacional contra España dirigida por los «rojos» españoles, las grandes potencias democráticas y las internacionales de la subversión. Por eso, cuando se decidió tomar alguna medida para contrarrestar las incesantes condenas al régimen español la estrategia elegida estuvo totalmente desenfocada. Las iniciativas ideadas desde la Asociación Cultural Hispanoamericana (entidad creada especificamente para promover las relaciones con el área) se basaron en valores antiliberales desprestigiados por la propaganda aliada al otro lado del Atlántico y en un antinortemericanismo incompatible con la euforia de la cooperación hemisférica que se vivía en América.

to "F. J. Castillo a Beigbeder, 6-12-39", en AMAE, R-1567/5; "Oliván a Beigbeder, 11-4-40", en AGA.AE. 9356; AGA.AE. 9362, 10079 y AMAE, R-1569/14.

${ }^{11}$ Un ejemplo muy claro fue la reacción de la iglesia argentina estudiado por A.A. EVERIGH: Nationalist Catholic Thought in Argentina, 1930-1946. Mons. Gustavo Franceschi and Criterio in the search for a post-liberal order. Unpublished Master Thesis. University of Oxford, 1990. 
Conforme pasaron los meses, el curso de la guerra, lejos de propiciar un mayor realismo, provocó la evolución opuesta en Madrid. Si hasta fines de mayo de 1940 la política de Beigbeder había sido ambigua, de gestos neutralistas y favores secretos a las potencias del Eje, desde entonces la euforia se apoderó de nuevo de casi toda la clase política del régimen -no sólo de los sectores falangistas, como se ha señalado a menudo-. El paroxismo prointervencionista y el entusiasmo ante la posible participación española en una inmediata victoria sobre las democracias europeas hizo soñar a los dirigentes españoles con reparaciones territoriales grandiosas. Este espejismo incitó una política hispano-americanista mucho más radical al considerar que también debía de estar próxima la hora de España en América.

La mayor equivocación fueron las iniciativas propagandísticas antinorteamericanas desarrolladas con motivo de la Conferencia de La Habana (julio de 1940), por resultar convergentes con la estrategia italoalemana que pretendía evitar cualquier medida que implicase el abandono de la neutralidad por parte de los paises americanos ${ }^{12}$. Además de incidentes antifalangistas, provocaron un cambio de política en el Departamento de Estado. Washington pasó a contemplar la influencia española en América como un potencial instrumento antiestadounidense en manos del Eje, en un momento en que parecía inminente la entrada de España en la guerra. Desde entonces, los mensajes e iniciativas hispanoamericanistas de Madrid, en cualquiera de sus vertientes (política, cultural, económica...), no sólo resultaron ineficaces en los países latinoamericanos, sino que comenzaron a ser juzgadas preventivamente como actividades beligerantes, fueron combatidas de una manera activa y llegaron a perturbar las relaciones bilaterales entre la España franquista y los EE.UU. Como derivación, el antifalangismo o antifranquismo se convirtió en parte de la política antitotalitaria de los gobiernos latinoamericanos, pues resultaba un marco perfecto de cooperación con Washington que no suscitaba oposición interna. Sin embargo, desde Madrid, el aparato diplomático

\footnotetext{
12 En dicha cumbre, los cancilleres americanos debian revisar las repercusiones de los acontecimientos europeos de junio en la defensa (militar e ideológica) y en la economía continental. Para la administración estadounidense era básico reafirmar el principio de no transferencia de las posesiones europeas en América y concretar la coordinación económica continental (estableciendo un gran cártel en torno a EE.UU.) a fin de disuadir a los totalitarismos de cualquier aspiración en la región y trabajar a un tiempo en favor de la preeminencia hemisférica norteamericana. La campaña española consistió en radiar a América conferencias antinorteamericanas y publicar en la prensa oficial todo tipo de diatribas contra los EE.UU. y contra Roosevelt: "El Acuerdo de la Habana y la Hispanidad", en Mundo, $n^{\circ} 13$ (4-8-1940); D.F.D.S., 852.9111/50; Mundo, n 9 (7-7 1940), $\mathrm{n}^{\mathrm{0}} 10$ (14-7-1940), $\mathrm{n}^{\mathrm{o}} 11$ (21-7-1940) y n¹2 (28-7-1940); Arriba, 1-8-40; Madrid, 2-8-1940.
} 
español seguía siendo incapaz de juzgar con ecuanimidad la realidad americana. Se negaba a admitir la evidencia de que los países latino-americanos aceptaban y respondían positivamente a las iniciativas de Washington.

El encumbramiento de Serrano Súñer en octubre de 1940 aún empeoró la situación. El "Cuñadísimo» era la cabeza visible de la germanofilia y de los defensores de una diplomacia ultranacionalista de molde fascista que preveía aprovechar la coyuntura bélica (con una inminente victoria alemana a la vista) y los modos renovadores del falangismo para hacer realidad el irredentismo español en Gibraltar y la expansión en el Norte de Africa. Aunque Franco ya hubiera refrenado el primer impulso beligerante fechado en junio, ante la opinión internacional Serrano significaba un paso más en el alineamiento pro-Eje de España, imagen que el propio canciller fomentaba con su lenguaje y con la "vacuna falangista» que intentó inocular en el aparato diplomático español.

Sus despliegues americanistas tradujeron a la perfección las tres coordenadas en que se movió toda su política exterior: los planteamientos teóricos descritos de una gran diplomacia al servicio de un estado totalitario; la utilización que Franco hizo de esa política progermana para sus designios generales de política exterior y, por último, la instrumentación de la diplomacia que el propio Serrano ensayó cuando fue perdiendo el control de otras esferas estatales de influencia política. En principio, la vertiente hispanoamericanista constituia, después de la vinculación italo-germana, el segundo polo de aquel amanecer de grandeza soñado en las proclamas falangistas. En palabras del embajador inglés en Madrid:

"Nadie que no haya vivido con este pueblo puede darse cuenta del valor que se concede a lo que llaman "Hispanidad". La razón es obvia. Aparte de razones políticas y geográficas, existe entre los españoles jóvenes el intenso deseo de repudiar el largo capítulo de las cuatro últimas centurias de historia de España y de crear un nuevo Imperio Español, no territorial, sino moral, intelectual y religioso. Tal concepción parece fútil y fantástica a los ojos de muchos en Europa y sobre todo en Sudamérica, sin embargo es una de las principales fuerzas en la politica de Falange $y$, ciertamente, uno de los objetivos primordiales de la política de Súñer" ${ }^{13}$.

Si tales ideas se conectan con las previsiones hechas durante el otoño de 1940 de una victoria del Eje en la guerra, es verosímil que en los primitivos diseños serranistas se vislumbrara la urgencia de adelantarse al 
triunfo alemán e ir preparando el terreno en América para evitar que los frutos de la victoria sobre el liberalismo mundial fuesen recogidos únicamente por Berlín y Roma en un área como la americana, donde España tenia «derechos de preeminencia» por razones históricas indiscutibles. Haciendo abstracción de la situación objetiva de América en 1940 se pudo mantener la ilusión de mostrar a América un proyecto político atractivo, en el sentido orteguiano, y alternativo al alemán o italiano, capaz de aglutinar a las naciones de raíz hispánica. Por primera vez en mucho tiempo, objetivos siempre entrevistos como factibles a largo plazo pasaron a tener más visos de realidad que nunca en razón de la coyuntura internacional. Por eso se percibió como urgente la necesidad de poner coto al considerado como ilegítimo imperialismo norteamericano que buscaba lograr la hegemonía continental con la campaña panamericanista aprovechando el aislamiento de las naciones americanas causado por la guerra. Tal imagen puede explicar, en parte, la resolución española de promover cualquier signo local de resistencia a los designios estadounidenses y de exasperar a la opinión pública latinoamericana contra Washington.

Esta hipótesis es complementaria con la funcionalidad inmediata que la vinculación hispanoamericanista pudo tener con respecto a la política alemana de Serrano -y de Franco- desde el otoño de 1940. Una forma más de hacer valer el papel de España ante Berlín era exhibiendo la influencia potencial del país sobre el mundo americano, a sabiendas de que tal capacidad era tenida en consideración por los alemanes como un útil más a emplear contra la creciente hegemonía norteamericana (y por tanto aliada) en la región ${ }^{14}$. Así pues, mientras se vislumbró la participación en la guerra, el Hispanoamericanismo militante también sirvió para amplificar la proximidad ideológica y política con el Eje. Cuando la opción de la beligerancia se desechó (desde fines de 1940), cobró nuevos sentidos. Por una parte, al igual que la acción de Tánger, pudo ser producto de la frustración parcial de las ambiciones españolas que supuso Hendaya: ya que no se habia logrado el reconocimiento del revisionismo español en Africa, la influencia sobre América era aún plausible sin exigencia de beligerancia, sin tener que tropezar con las reivindicaciones de otros amigos europeos y a bajo costo, pese a no ser ya sus frutos tan inmediatos. En el ámbito

14 D.F.D.S., 652.1115/95 y FO. 371/26954; R. POMMERIN: Das Dritte Reich in Lateinamerika: die deutsche Politigegenüber Süd und Mittelamerika 1939-1942. Dusseldorf, 1977, p. 201. Cantalupo señaló que entre las escusas que utilizaron los medios oficiales españoles en enero de 1941 para justificar su no intervención en la guerra estaba la de que si España mantenia su no beligerancia podia contribuir a favorecer la propaganda del Eje en América Latina: R. CANTALUPO, Fu la Spagna. Milano, 1948, p. 301 apud M. Mugnan, Op. cit., p. 291 
simbólico (de legitimación política), el que España recuperase su prestigio cultural en América y se erigiera allá en la representante mejor cualificada de la nueva Europa conformaba un leit motiv complementario de las reivindicaciones africanas y gibraltareña o podía sustituirlas en caso de que la consecución de éstas fuese diferida si se posponia la beligerancia ${ }^{15}$.

Por otra parte, tampoco se puede descartar la idea de que alguno de los ensayos de relanzar un hispanoamericanismo más falangista (el del verano de 1941) estuviera conectado a los conflictos políticos domésticos, en especial a la carrera de Serrano por mantener su poder o su proyecto político. Finalmente, como provocara la inmediata malquerencia norteamericana hacia Madrid, la política de la "Hispanidad" pudo funcionar como parte de los gestos de "apaciguamiento" ante Alemania que ayudaron a dilatar la beligerancia española y responder a las necesarias concesiones o muestras de amistad que se debían seguir prestando a Alemania e Italia. Así sucedió a principios de 1941, cuando la presión alemana era más fuerte y se negociaban acuerdos económicos con los aliados, y a principios de 1942, cuando se asumió la representación de intereses de ambas naciones en muchos países americanos. $Y$ asi lo contemplaron también desde esa fecha los medios diplomáticos norteamericanos, convencidos de que buena parte del antinorteamericanismo e incluso de la política de Hispanidad serranista podía estar siendo usada como un instrumento para aplacar a Berlín.

Con todo, en ningún caso se accedió a efectuar campañas de propaganda conjuntas con el Eje en América durante el mandato de Serrano. $\mathrm{Ni}$ el Ministro, ni los representantes, ni siquiera el aparato serranista de la Subsecretaría de Prensa y Propaganda en el Ministerio de Gobernación (con Tovar al frente) consintieron. $Y$ eso que las propuestas alemanas para financiar conjuntamente diarios, revistas, a publicistas y escritores fueron relativamente numerosas. Aunque hay referencias a la firma (marzo de 1941) de un supuesto compromiso de propaganda conjunta

\footnotetext{
5 Ch. Haltead estima que, tanto la acción de Tánger, como la campaña en torno a la Hispanidad, fueron "gestos quijotescos" realizados a sabiendas de las represalias económicas anglonorteamericanas que se sabia iban a costar: "eran testimonio de la fidelidad de los líderes de la Nueva España a los pincipios [se refiere al componente nacionalista] a partir de los cuales habian fundado su régimen" Vid. CH. HALSTEAD: Spain. the Powers and the Second World War. University of Virginia, Ph.D., 1962, p.384 y 432. También L. DELGADO, Op . cit., pp. 429-30 recoge esta idea del "imperialismo frustrado" y señala acertadamente que la multiplicación de publicaciones falangistas sobre el tema de la Hispanidad no pudo ser gratuita, sino que debió responder a la necesidad de compensar un revisionismo africano que, conforme avanzaba la guerra parecia más lejano.
} 
(rubricado por Tovar y el alemán Schmidt) que contemplaba la colaboración a través de la agencia EFE, nunca hubo voluntad de cumplirlo por parte de ninguna de las instancias del régimen (al menos no de las directamente vinculadas a Serrano). Las respuestas oficiales españolas fueron siempre denegatorias. La mayoría de los diplomáticos desaconsejaron cualquier movimiento en tal sentido. Casi todos se ofendian cuando la prensa insinuaba colaboraciones de ese tipo. El juicio emitido por Tovar a petición de las más altas instancias de Exteriores en 1941 fue rotundo:

"Estimo que la actuación de nuestro agente oficioso en México debe ser independiente de otros elementos, incluso de los de propaganda alemana; ya que, de ese modo, se evitarian suspicacias que, desde luego, vendrian a entorpecer nuestra labor en pro de la Hispanidad" 16.

Durante el mandato de Serrano se mantuvo la noción de que América constituía un ámbito de influencia exclusivamente española y nunca se aceptó la idea de servir como "puente" de otras ascendencias foráneas - por muy amigas que fueran - en aquel continente; lo que no obsta para que tal imagen pudiese haber sido explotada en algunas negociaciones. El mismo nacionalismo radical que reflejaban las proclamas hispanistas de Serrano exacerbó la conexión entre política exterior y orgullo nacional arraigada durante décadas en el servicio exterior español, por lo que el sentimiento más extendido acerca de la relación con América excluía expresamente la cooperación de Falange con los nazis en la región.

En cualquier caso, desde octubre de 1940 el ministro trató de impulsar las relaciones con América Latina a través de una triple vía: la vigorización de los cauces diplomáticos, la potenciación de Falange Exterior y el relanzamiento de una política cultural de contenidos más políticos, cuyo organismo-bandera debia ser el Consejo de la Hispanidad. Las filiales falangistas americanas debían encargarse de mantener los órganos de propaganda extradiplomáticos y de conservar el hálito falangista entre las colonias. El Consejo de la Hispanidad, nueva entidad oficial asesora y dependiente del Ministerio de Asuntos Exteriores, debia orientar toda la

16 "Tovar al Subsecretario, 31-1-1941" y “Cárdenas a Serrano, 24-11-40", en AMAE, R1433/1; “Súñer a Serrano, 26-11-40», en AGA. AE. 9362; “Luca Tena a Serrano, 13,16 y 24-11941 ", en AGA.AE 9358 y AMAE, R-1799/6 y diversas notas en AGA.C 243 y 245; R. POMMERIN, Das Dritte Reich..., pp. 297-8 y R. GarRiga, La España de Franco..., pp.290-1. Ni se cumplió el acuerdo Schmidt-Tovar, ni un plan análogo para cooperación cultural hispano-italiana en América y el mundo islámico, formulado en octubre de 1941: "El embajador de Italia a Serrano, 1-101940 ", en AMAE, R-2170/1. 
política hacia la región y su creación fue presentada como el inicio de una nueva fase en las relaciones con América.

La nueva combatividad hispanoamericanista del régimen -que persistió en el tono antinorteamericano de sus iniciativas - fue tan ineficaz como contraproducente. Resultó imposible resucitar las filiales falangistas y el Consejo de la Hispanidad no llegó a realizar actividad alguna en América en uno de los años de mayores dificultades financieras del régimen. Pero aun cuando no se ejecutara ninguna iniciativa relevante en concierto con el Eje, las proclamas de Serrano, arropadas por la evolución fascistizante del régimen, tuvieron varios efectos negativos de larga duración. Provocaron que Washington promoviese medidas continentales especificas contra las actividades españolas. Desde octubre de 1940 el Departamento de Estado optó por penalizar tanto las actividades paraestatales españolas como las gubernamentales. Los diplomáticos norteamericanos debian restringir su trato con los representantes del Eje (incluídos los españoles) e informar de cualquier cambio en el personal diplomático de los países totalitarios, procurando animar a los gobiernos americanos para que fiscalizaran las actividades extraprofesionales de funcionarios del Eje (y de España) en América. La medida guardaba una lógica aplastante:

"Falange es peligrosa por su numerosa afiliación y por sus doctrinas antinorteamericanas y pronazis. Aunque no se ha probado que la organización haya promovido acto alguno de sabotaje o espionaje, todos los indicios hacen pensar que su eficaz y extensa organización constituye el marco idóneo para una fuerte "quintacolumna" que se podría comprometer en actos de sabotaje a gran escala en caso de guerra (...) y sus actividades tienden a poner en entredicho el ideal democrático común interamericano. Teniendo en cuenta que las embajadas españolas cooperan y comparten el liderazgo con la organización falangista en la difusión de tales ideas, se considera que también aquéllas trabajan contra el ideal democrático del Hemisferio Occidental» 17.

Cuando en noviembre llegaron rumores a Washington de que España habia llegado a un acuerdo formal con Alemania para conducir una campaña propagandística antinorteamericana y prototalitaria en América Latina, se aprobó el informe "España. instrumento de penetración del Eje en los países hispanoparlantes». En él se asumia la existencia de planes para utilizar a España como canal de propaganda totalitaria. Era necesario evitar que la potencial amenaza española se convirtiera en un peligro serio para el hemisferio occidental. La primera medida fue centralizar el sistema de información sobre actividades falangistas en el continente $(y$ en

17 D.F.D.S., $701.5237 / 51 ; 800.20210 / 669$ y $800.20210 / 596$ 
Filipinas) creando archivos especiales en las secciones del Departamento de Estado, a fin de detectarlas y neutralizarlas. A la par, se apostaba por alentar el programa dirigido a reforzar los lazos económicos y culturales con las otras repúblicas americanas ${ }^{18}$.

En diciembre el Subsecretario de Estado Welles advirtió al embajador español Cárdenas que las actividades de "Hispanidad" constituían un obstáculo para la aprobación de la ayuda económica norteamericana que se estaba negociando. Una de las cuatro condiciones para continuar las conversaciones bilaterales era el cese de ataques en la prensa y otras manifestaciones de hostilidad hacia los Estados Unidos, bien en España o bien de fuentes españolas en los países hispanohablantes del hemisferio americano. A partir de enero de 1941 el criterio oficial sobre la política española en Hispanoamérica no se modificó: como España mantenía una política de colaboración y solidaridad con el Eje, así como una actitud enemiga y hostil hacia Washington por sus relaciones con América Latina, toda actividad española en la región, bajo cualquier forma, debía ser vigilada y contrarrestada. Las actividades franquistas vinculadas con el catolicismo también:

\begin{abstract}
"Es un hecho que los exponentes locales de la Hispanidad confian firmemente en la expansión del sentimiento de Hispanidad en América Latina en la creencia de que existe una creciente tendencia de apoyo al mismo en el seno de la iglesia (en especial de la juventud católica) de los paises hispanoamericanos. Las Juventudes de Acción Católica pueden convertirse en un exponente de la Hispanidad mucho más exitoso que la Falange Exterior» ${ }^{19}$.
\end{abstract}

18 Los contactos económicos, culturales y políticos de los EE.UU. con las repúblicas latinoamericanas siguian su camino con éxito. Antes de enero de 1941, los EE.UU. habian firmado acuerdos militares con todas las repúblicas latinoamericanas (excepto Argentina) y habian creado en ellas agregadurias militares. Las misiones militares de países del Eje habian sido expulsadas y, utilizando la compañía Pan American, se ejercia algun tipo de control sobre casi todas las lineas aéreas continentales. La ayuda económica norteamericana, imperceptible hasta fines de 1940 , comenzó a llegar a los distintos países en forma de asistencia para la defensa, la construcción de comunicaciones o de planes de estabilización monetaria. Las Agencias creadas para adquirir materias primas estratégicas (cobre, caucho, cromo, tungsteno, etc.) rubricaban sus primeros convenios y los EE.UU. se hacian cargo de los stocks de algunas cosechas vitales para las economias de monocultivo. Se celebraron conferencias regionales para coordinar las economias de los paises del Rio de la Plata (febrero de 1941) y del Caribe (abril) y, por lo que se refiere a las relaciones culturales, el vasto programa diseñado durante el verano de 1940, que disponia de un millón de dólares para el ejercicio de 1941, funcionaba a pleno rendimiento en la primavera de ese año: R.A. HUMPhREYS, Op. cit., Vol.I, pp.90 y ss.; M. EsPINOSA, Op. cit., 165 y ss.

19 D.F.D.S., 852.00/9562, 852.00/9642, 852.9111/79, 740.0011/23429, 800.20210/667, $800.20210 / 667$ y F.R.U.S., 1940. Vol.II, pp.845-7, 850 y 852 . Esta línea intransigente emanaba de la poca confianza que el régimen español siguió mereciendo al Secretario de Estado Hull en los primeros cuatro meses de 1941, hasta el punto de negarse en ese periodo a aceptar la línea 
El cambio de la política norteamericana coincidió con las primeras medidas adoptadas por Gran Bretaña contra la "propaganda alemana bajo cobertura española en América Latina" ${ }^{20}$, reforzadas con la colaboración del exilio republicano en América y asociaciones y partidos proaliados locales que suministraban a los servicios de información anglosajones todo tipo de noticias (por lo general falsas) acerca de la colaboración nazifalangista en el continente.

En consecuencia, el rechazo de la opinión pública latinoamericana fue casi unánime. Aunque las respuestas gubernamentales no llegaran a ser univocas a la hora de realizar gestiones colectivas para evitar la beligerancia de Franco al lado del Eje, la réplica de los medios de comunicación fue apabullante, con condenas sin paliativos al régimen español y a sus objetivos en la región ${ }^{21}$. Para sorpresa de los franquistas, cada vez fueron menos los diarios, periodistas y, sobre todo, los hombres de estado dispuestos a mostrar su simpatía por la España de Franco por temor a acusaciones de "quintacolumnismo". Significados diarios de la derecha latinoamericana ( $E$ / Comercio peruano, por ejemplo) que habian ensalzado a Franco durante la Guerra Civil, incluian ahora en sus páginas informaciones contra un régimen en el que sólo veían un aliado de Hitler. Lo mismo sucedia con publicaciones vinculadas a las colonias españolas como era el Diario de la Marina, que había sido fiel al régimen desde 1936 y ahora se despegaba de la línea antinorteamericana de Madrid. Por su parte, la iglesia católica latinoamericana y sus órganos periodísticos habian proseguido su distanciamiento con respecto al régimen franquista por la política cada vez más estatista de éste, en la linea de los totalitarismos condenados por el Vaticano. Conforme se popularizó el lema de la defensa de la democracia frente al nazi-fascismo, la posición de Maritain fue adquiriendo un mayor eco en el continente, especialmente entre las nuevas agrupaciones políticas de inspiración católica. En general, la polarización de la opinión pública motivada por la propaganda bélica llevó a un rápido y radical distanciamiento de los fascismos europeos en el que no cabian los matices. El 'comentario de un diplomático franquista acerca de la evolución de un destacado político costarricense es bastante ilustrativo de las actitudes que se generalizaron desde 1941:

británica de apaciguamiento que Londres ejercitaba con Franco (con créditos y comercio) y que el embajador Weddell defendia desde Madrid como el instrumento idóneo para debilitar la posición de Serrano y contrarrestar la influencia alemana: F.R.U.S.. 1941, Vol.II, pp.880-891.

20 F.O., $371 / 24528$ y $371 / 26954$.

21 Una muestra fue el primer opúsculo propagandistico antifalangista: Una voz de Alerta frente a la amenaza del Falangismo en Cuba (La Habana, noviembre de 1940) del senador A. Cruz 
«D. Teodoro Picado es conocido por sus tendencias derechistas y sentimientos católicos. Durante nuestra Guerra Civil fue un gran entusiasta del Generalísimo Franco, aunque hoy - como casi todos nuestros simpatizantes de aquella época- a consecuencia de la guerra europea, de las tendencias anglófilas de este país y del ambiente que se ha hecho alrededor de la llamada "defensa de las democracias", si sigue teniendo esas mismas simpatías por nuestro Caudillo, procura disimularlas, o por lo menos no las exterioriza: de hacerlo, le llamarian totalitario o quintacolumnista y le anularian políticamente dentro de su pais" 22.

Hasta los compatriotas de simpatías profranquistas se desmarcaron de la trayectoria antidemocrática que seguía Madrid e hicieron públicas profesiones de fe democrática ante las autoridades de los paises en que residian. El ensayo de reconstruir la Falange Exterior sólo sirvió para ocasionar gravisimos incidentes en una de las escasas filiales con actividad: la cubana, que fue prohibida. El resto de las sucursales del partido sufrieron serias dificultades en los últimos meses de 1940 y principios de 1941. Falange tuvo que ser disuelta en Puerto Rico, como lo había sido en Panamá y Colombia por la dispersión de sus antiguos miembros. La situación se repetía en el resto de Centroamérica, mientras las filiales del Cono Sur tomaban las máximas precauciones en previsión de similar desenlace ${ }^{23}$.

Las sospechas y acusaciones sobre las actividades falangistas en América no hacian más que acentuar la inseguridad y las contrariedades que sufrían las colonias de residentes españoles en el área, cuya situación económica se había agravado desde octubre de 1940. Los comerciantes, artesanos o industriales españoles arrostraban las consecuencias del alza de precios, las dificultades de suministro, la carestía de las importaciones e incluso las listas negras inglesas. Se sentian amenazados al contemplar la suerte de otros grupos nacionales (japoneses, alemanes o italianos) sobre los que recaian restricciones tan duras que en ocasiones les impedían ejercer el comercio. Entretanto, la situación de los españoles más pobres (muchas veces en el paro) se hizo tan desesperada que su única salida fue intentar la repatriación; sobre todo cuando las sociedades de

22 "Mora a Serrano, 1-5-41", en AMAE, R-1432/11.

23 AMAE, P-345/24.378; “Espelius a Serrano, 11 y 17-2-41", en AMAE, $R-1432 / 10$ y $R$ 1799/6; "Serrano al encargado de negocios cubano, 25-1-41 y 6-3-41", en AMAE, R-1577/37 y $R$ 1886/11; D.F.D.S., 737.52/17; "Cárcer a Cárdenas, 24-9-1940", en AGA.AE 8727; "Serrano a Sandoval, 16 1-41", en AMAE, R-1569/2; "Arcos a Serrano, 12-12-40 y 11-241", en AMAE, R1569/9; D.F.D.S., 852.20221/2. En enero de 1941 se inauguró "Fundación Española", trasunto de Falange en Uruguay y la Casa de España en Argentina: AMAE, R-1569/14 y AGA.AE 10078; "Magaz a Serrano, 17-4-41", en AMAE, R-1910/43 
beneficencia españolas a las que pertenecian habian quedado bajo control de compatriotas de signo político contrario, lo que había supuesto su expulsión. Fueron continuas las peticiones de fondos para afrontar las repatriaciones de indigentes, las consultas sobre la conveniencia de recomendar a los españoles su nacionalización en los países de residencia (siguiendo el ejemplo italiano), los controles oficiales sobre el precio de los pasajes marítimos de tercera y las órdenes a los representantes para que prestasen auxilio a los falangistas que se encontraran en apuros con autoridades americanas. Sin embargo, lo peor estaba por llegar.

Los despachos de todas las representaciones franquistas informaban sobre la gravedad de la campaña, el tono envenenado de la prensa continental y las reacciones airadas contra España, su régimen y su caudillo que suscitaban las noticias de Madrid. Embajadores significados recomendaban tacto y prudencia en las manifestaciones oficiales franquistas. Desde el otoño de 1940 los informes diplomáticos ya no se regodeaban subrayando los signos de resistencia continental a los EE.UU.. Recogian con pesadumbre los éxitos de Washington en su política de captación sobre los países de origen hispánico, en especial los logros de instituciones y programas culturales:

«El parangón entre el espacio vital, que envuelve la idea de dominio, y el espacio espiritual, lo mismo que mezclar en ese parangón a Hispanoamérica con Africa, suena muy mal en los oídos argentinos. Estamos en un período sumamente delicado para hacer una obra seria y provechosa de acercamiento espiritual. Una torpeza de nuestra política de captación, puede comprometer y aun destruir lo que aquí existe de Hispanidad. No hay que olvidar que estos países ( $y$ yo debo referirme especialmente a la Argentina) desconocen el problema europeo y la necesidad que alli existe de sustituir el viejo y desacreditado sistema liberal y parlamentario (...). No hay que olvidar que Inglaterra tiene en esta república grandes intereses y que Norte América, con su enorme propaganda de radio, agencias, prensa y cinematógrafo, contraria a los países totalitarios, hace sospechoso cuanto viene de ellos" ${ }^{24}$.

Algunos diplomáticos apostaban por la inactividad total, pues ante el imparable ambiente político de «Panamericanismo frente a Iberoamericanismo, Democracia contra Dictadura, Libertad contra Totalitarismo o el llamado Cristianismo contra el Catolicismo", que Washington alentaba, lo mejor para no perder tiempo y dinero era callar y esperar el resultado de la guerra ${ }^{25}$. Pero Madrid no reaccionó a tiempo. La evolución política interna e internacional lo impidió.

24 "Magaz a Serrano, 17-4-41», en AMAE, R-1910/43

25 "Arcos a Serrano, 8-4-41», en AMAE, R-1569/9; "Magaz a Serrano, 3-12-40", en AMAE, R 
En la primavera-verano de 1941, Serrano ensayaba desde el Palacio de Santa Cruz un último golpe de efecto falangista y proalemán para enderezar su posición política interna y tal vez para restaurar su imagen y la del estado franquista ante Berlín. Todo ello cuando España acababa de firmar unos acuerdos económicos con Gran Bretaña y Hitler lograba espectaculares avances militares, primero en los Balcanes y luego en la URSS. El envío de la División Azul se acompañó de una nueva ofensiva de "hispanoamericanismo azul", con Falange Exterior como instrumento estelar y un Consejo de la Hispanidad renovado con un flamante presupuesto de más de 3 millones de pesetas.

La plasmación efectiva de estos proyectos en América fue insignificante y lo poco que se hizo volvió a tener el carácter cultural y católico de siempre. Pero, a pesar de su inocuidad, el mero anuncio de nuevas iniciativas hispanoamericanistas comportó un endurecimiento de la política estadounidense contra los movimientos españoles, respaldado por el resto del hemisferio con la excepción de Argentina y Paraguay. Hasta los alemanes estimaron exagerado el tono falangista y belicista del hispanoamericanismo de Madrid en el verano de 1941, cuando rumores de conspiraciones nazis - nunca demostradas - provocaron la expulsión de diplomáticos alemanes en muchos paises ${ }^{26}$. Hubo graves problemas con Falange en Uruguay y Cuba, país que estuvo a punto de romper relaciones con España. En el resto de las repúblicas las filiales de Falange ya habian dejado de existir o estaban desarticuladas, a la espera de la orden de disolución formal. Por otra parte, las esperanzas depositadas por el gobierno español en los grupos nacionalistas argentinos no fructificaron y los otros patrocinadores solventes de la Hispanidad franquista (sectores del Partido Conservador colombiano y del Partido Nacional uruguayo) se encontraban en la oposición.

Sólo entonces hubo un cierto repliegue oficial del Hispanoamericanismo, en un proceso paralelo al declive del "Cuñadísimo" y de su

1467/12; “Súñer a Serrano, 21-1-1941", en AGA.AE. 9358 y’ "Sangróniz a Serrano, 27-12-40 y 18 3-1941", en AGA.AE. 11834 y 11835.

26 Asi lo atestigua R. Garriga, quien advirtió a Serrano a fines de julio de 1941 que en Berlín no se entendían los excesos españoles sobre el Imperio: "Yo le decía [a Serrano Súñer] que los alemanes no comprendian por qué se hablaba tanto de Imperio si resultaba que España no podía mandar tan sólo una máquina de escribir o un aparato de radio a Buenos Aires o México, sino que hoy dia son los argentinos y los mexicanos quienes pueden enseñar a los españoles cómo se construye bien y rápido un puente o una carretera. "Realmente hemos exagerado demasiado y ya daré orden de no hacer tanto el ridiculo", me replicó tomando una nota en su carnet", en R. GarRiAgA, La España de..., vol.I, p. 347. 
proyecto político. Madrid comenzó a desistir de su idea de ejercer influencia en América. Serrano revisó su política y envió órdenes de moderación y prudencia: intentar mantener los escasos reductos de simpatizantes que quedaban con una política estrictamente cultural y católica. Pero era demasiado tarde: los EE.UU, entraron en la guerra y estaban menos dispuestos que nunca a permitir que España pudiera realizar el trabajo propagandístico subversivo (antinorteamericano) del Eje en América. Además Washington utilizó la amenaza nazi-falangista como argumento de la amplia campaña propagandística puesta en marcha para que la opinión pública continental aceptase la beligerancia de los EE.UU. y del resto de los gobiernos tras la Conferencia de Rio (enero de 1942). En adelante, los servicios de inteligencia estadounidenses fomentaron directamente actitudes antifranquistas radicales en todo el hemisferio filtrando informaciones sobre el uso alemán de la conexión española en América y financiando algunas actividades de la oposición republicana.

Hasta octubre de 1942 la Hispanidad del régimen inició su repliegue hacia cauces más tradicionalistas: apenas se realizaron algunas actividades de carácter católico, lo más despolitizadas posible, o de contenidos anticomunistas. No sirvió de nada. El compromiso de la protección de intereses de los paises del Eje y las operaciones comerciales concertadas con Argentina en febrero de 1942 provocaron nuevas suspicacias. La campaña antiespañola - como la denominaban los diplomáticos franquistas-arreció. Las relaciones con Cuba y Nicaragua estuvieron al borde de la ruptura y las colonias de españoles leales al régimen sufrieron amenazas, chantajes, denuncias de espionaje y más inclusiones en las listas negras. Todo ello a pesar del deshielo entre Madrid y Washington que Serrano patrocinó desde la primavera de 1942. La perplejidad de la diplomacia española era tanto mayor cuanto que la campaña antiespañola era inversamente proporcional a la intensidad de las actividades franquistas en América. El balance de la gestión de Serrano se cerraba con un panorama desolador: las filiales falangistas se habian desintegrado y el Consejo de la Hispanidad había sido una especie de fantasma ruidoso inoperante en América. Cualquier ensayo propagandístico suscitaba acusaciones de quintacolumnismo porque sólo tenia eco entre los sectores ultracatólicos y antiliberales latinoamericanos, los menos proclives a la alianza continental patrocinada por los EE.UU., y en un gobierno como el argentino, sospechoso de totalitarismo por su enfrentamiento a Washington. Se había consumando el alejamiento de casi todos los sectores de las sociedades americanas que en algún momento desde 1936 habían simpatizado con el Franquismo. Como meses después señalaba un diplomático español: 
"No hemos recogido más amigos que los disidentes, los enemigos del Gobierno y los enemigos de los Estados Unidos. ¿Nos conviene aparecer como enemigos de los gobiernos constituidos? ¿Nos conviene aparecer como enemigos naturales de los Estados Unidos? ¿Puede admirarnos mucho que, en estas condiciones, tanto el Gobierno de Nicaragua como el de Washington nos miren con recelo y desconfianza? Creo honradamente que nosotros, en su caso, haríamos lo mismo" 27.

La vuelta de Jordana al Palacio de Santa Cruz dio mayor credibilidad al giro de la política española en América que habia iniciado su antecesor. Convencido de la necesidad de una política exterior más independiente y neutral que pudiera salvaguardar al régimen de las contingencias del sistema internacional, convirtió al hispanoamericanismo - con el catolicismo, el anticomunismo y la relación con Portugal- en uno de los instrumentos para marcar distancias con el Eje e introducir cauces de distensión con los aliados, en especiakgon los EE.UU. Hubo que renunciar públicamente a competir con Washingtón en el logro de una esfera de influencia política en el continente y tratar de demostrar el carácter inofensivo de los despliegues españoles en la región, haciendo creible la neutralidad española y optando -durante meses - por la más absoluta inactividad. Jordana no sólo se encargó de seguir "siendo bueno" sino que se aseguró de "parecerlo»: el protagonismo falangista quedó zanjado para siempre y el Consejo de la Hispanidad pasó a ser una instancia completamente intervenida por el Ministerio de Exteriores. Las consignas de prensa difundidas a petición de Exteriores reflejan los cambios:

"Se explicará que para España la palabra «raza» tiene un valor espiritual que recoge la tradición histórica de un pensamiento, una cultura y una concepción de la vida difundidas por España en el continente americano. Son de nuestra raza las que participan en ese espiritu aunque procedan genealógicamente de otros orígenes. Este es el verdadero sentido de la Hispanidad que se sitúa en un elevado plano de comunidad espiritual. La Fiesta de la Raza no tiene, nada que ver con consideraciones de política interior o internacional de los paises de nuestra estirpe, cuya independencia es absoluta y cuya libertad de orientarse en el interior y en el exterior en nada roza a aquella unidad espiritual. Conviene expresar todo el valor sustantivo del catolicismo en la formación de este concepto espiritual de la raza española (...). Evitar toda referencia a la guerra actual, evitar la palabra imperio, evitar todo lo que pueda interpretarse (aún torcidamente) en el sentido de que España desearia ocupar una posición tutelar respecto a los paises de nuestro idioma» 28.

\footnotetext{
27 «Mora a Jordana, 4-12-43", AMAE, R-2439/38. Curiosamente, en nota manuscrita escrita al margen se podia leer: "este despacho revela en su autor un estado de ánimo muy deprimido".

28 AGA.C. 126.
} 
Pero, ni la despolitización de los productos culturales (los únicos exportados por Madrid) ni siquiera la benevolencia norteamericana lograda a partir de la primavera de $1943^{29}$ fueron suficientes para obtener resultados positivos. En la condena al régimen de Franco, la opinión pública continental defensora de valores democráticos sobrepasó desde entonces las posiciones más moderadas del Departamento de Estado y del Foreign Office. El esfuerzo por limpiar las imágenes de colaboración con el Eje del pasado resultó fútil. La publicación y difusión continental del libro de Allen Chase, Falange. The Axis Secret Army in the Americas (Nueva York, 1943), cuidadosa acumulación rumores y denuncias antifalangistas, fue todo un símbolo.

El posterior endurecimiento de la política aliada hacia Franco (en especial, a partir de la suspensión de envios de petróleo en enero de 1944), volvió a recrudecer las acusaciones y los rumores antifalangistas en América: conexiones españolas en el golpe revolucionario boliviano del M.N.R., colaboración con el espionaje alemán en Argentina, etc. En América se asistía a una oleada de conmociones políticas que acabaron con regímenes autoritarios o dictatoriales como los de Peñaranda (Bolivia), Hernández (El Salvador), Ubico (Guatemala) y Arroyo del Río (Ecuador). El resultado de las elecciones en Cuba o Costa Rica tampoco depararon sorpresas agradables al régimen. Argentina seguia siendo el único país con el que se mantenía una relación fluida en 1944, aunque con el paso del tiempo esta vinculación acentuó las dificultades con los EE.UU. ${ }^{30}$.

La necesidad de vadear las presiones anglosajonas terminaron convirtiendo la política en la región en mero instrumento del acercamiento ensayado hacia las potencias aliadas. Desde el discurso de Churchill del 24 de mayo de 1944 hasta la primavera de 1945, el régimen viró su atención hacia Gran Bretaña soñando con un acercamiento sobre la base del anticomunismo. Esta esperanza y la de conseguir la aceptación de Washington conformaron las líneas básicas de acción de Lequerica. En su búsqueda de ámbitos de cooperación con los anglosajones, el ministro

29 El Departamento de Estado comenzó a asumir los juicios de su embajador Hayes (compartidos por el Foreign Office) de que una mejora de las relaciones hispanoamericanas favorecería el camino español hacia la neutralidad e instruyó a sus representantes en América Latina para que moderaran su predisposición antiespañola: D.F.D.S. 852.00/10327, 852.00/10381 y $852.00 / 10159$.

30 Sobre la relación bilateral con Argentina, Vid. M. GONZALEZ DE OLEAGA: Las relaciones hispano-argentinas 1939-1946. Identidad. ideología y crisis. Tesis doctoral inédita, Madrid, Unv. Complutense, 1990 y M. QuIJADA: Relaciones hispano-argentinas 1936-1948. Coyunturas de crisis. Tesis doctoral inédita, Madrid, Unv. Complutense, 1989. 
habló de la "coordinación atlántica». Con el lema de "el Atlántico nos une", reclamó una amistad hispano-inglesa que sirviera como el anclaje de España en la vertiente europea de la cubeta atlántica. Los múltiples nexos ibéricos con sus antiguas colonias, el propio Bloque Ibérico, la unidad panamericana, más las alianzas anglosajona y angloportuguesa, tejerian una tupida malla de relaciones de la que todas las partes obtendrían beneficios. Además, se confiaba en la efectividad de una campaña hispanoamericanista como vía para intimar con Washington ${ }^{31}$.

Desde el otoño de 1944 se multiplicaron las iniciativas de diversos sectores sociopolíticos latinoamericanos ante sus respectivos gobiernos en favor de una ruptura de relaciones con Madrid. Mas, en el Palacio de Santa Cruz costaba trabajo admitir que la propaganda antifascista desplegada en el continente durante los años anteriores pudiera seguir cerrando el paso a las iniciativas franquistas si éstas se mantenian en términos católico-culturales ${ }^{32}$. Ni se contempló como probable un inmediato enrarecimiento de la actitud norteamericana, ni se advirtió con la suficiente antelación el duro trance que esperaba al régimen desde la primavera de 1945 , cuando el ostracismo formal por el que se decidieron las grandes potencias estuvo a punto de verse desbordado en los foros internacionales (Conferencia de Chapultepec y San Francisco) por las acciones de los paises latinoamericanos. Las maniobras del exilio republicano no fueron ajenas a ello. La nueva situación obligó a un replanteamiento de la política en la región desde abril-mayo de 1945: una estrategia defensiva de contrapropaganda a gran escala que pasó a ser una de las prioridad del régimen. Desde julio de 1945 la política de Artajo tuvo que abandonar los proyectos tradicionales de búsqueda de una esfera de influencia en aquel continente, en favor de pequeñas metas diplomáticas que contribuyeran a la estabilidad del régimen y a paliar su aislamiento internacional.

En agosto de 1945, el balance diplomático era pésimo. Aunque sólo tres paises (México, Guatemala y Panamá) hubiesen roto relaciones con Madrid (a ellos se unieron Bolivia en septiembre y Venezuela en octubre), la mayoría de las representaciones diplomáticas latinoamericanas en España estaban vacantes o estaban servidas sólo por encargados de negocios (Nicaragua, Paraguay, República Dominicana, Ecuador y Colombia, entre otras), pendientes del nombramiento de diplomáticos. Ni siquiera los

31 "Entrevista de Associated Press a Lequerica, 1944", en AMAE, R-1370/5; D.F.D.S., 852.00/12644 y 852.00/10-1044; “Circular n” 34, 26-2-45”, en APG.JE. 5/2.1; “Circulares 46 a 52 : marzo de 1945", en AGA.AE. 10100.

32 D.F.D.S., $852.00 / 9-1344$ y $852.00 / 12-1344$ y $710.52 / 11-2844$. 
contactos comerciales se habían normalizado. Un convenio de pagos negociado con Cuba desde 1943 seguía pendiente y hasta la vinculación hispanoargentina se habia debilitado, pues el gobierno de Buenos Aires había mejorado sus perspectivas económicas y podía prescindir un cliente tan poco cumplidor como España. En tres años (desde 1942) el agregado agrónomo enviado a Sudamérica no había podido tomar posesión en cuatro de las diez repúblicas a las que habia sido destinado y otro tanto habia sucedido con los corresponsales de la agencia EFE. Existían serias dificultades para la difusión del material de propaganda cultural y casi todos los países del área parecian dispuestos a respaldar una condena internacional al régimen.

En el fracaso politico descrito, desde los grandiosos planteamientos de 1939 hasta la estrategia defensiva de la primavera de 1945, el factor que más llama la atención es la ceguera de los dirigentes españoles a la hora de juzgar con ecuanimidad la realidad americana. La sobrevaloración de la capacidad nacional de influencia impidió reconocer a tiempo que la hora de España en la región no iba a llegar nunca y que la hegemonía estadounidense era imparable. Los esquemas mentales moldeados en la estela del 98 contenían una vertiente de antinorteamericanismo de la que fue muy difícil despojarse y ese prejuicio hizo imposible una evaluación objetiva de las consecuencias reales de acontecimientos tales como las conferencias panamericanas. También llevó a considerar a los enemigos de Washington como aliados potenciales. La superioridad casi metropolitana desde la que se contemplaba a las sociedades americanas, además de inducir a un exceso de confianza en la eficacia de armas como la difusión ideológica, cultural y religiosa, hacía que se menospreciaran las noticias negativas recibidas del otro lado del Atlántico. El paternalismo y, en ocasiones, el desdén que aparece en los juicios de los diplomáticos ocultaban la resistencia a reconocer la mayoría de edad de los estados latinoamericanos y, por tanto, la independencia de sus acciones. Por eso cada vez que aquéllos reaccionaban de forma antagónica a las iniciativas de Madrid, se tendía a responsabilizar a agentes y elementos externos (el exilio, el poder de Washington, la fuerza del comunismo, etc.) desviando la atención de la raíz del problema. Nunca se ponía en duda la creencia ciega en la ilimitada capacidad de Madrid de convertirse en foco de atención y atracción de los latinoamericanos con las iniciativas grandilocuentes diseñadas por Madrid. La denominación de la sección encargada de los asuntos americanos como "Ultramar» hasta 1944 no puede considerarse casual. Tal vocablo tenía unas connotaciones imperialistas que decian mucho de aspiraciones más o menos inconscientes a las que nunca se había renunciado. 
La política que se elaboró desde Madrid tuvo poco que ver con la realidad americana. La extracción socio-profesional de los diplomáticos españoles junto con la uniformidad ideológica impuesta tras la depuración efectuada con la Guerra Civil y la irregularidad organizativa casi permanente de la sección del Ministerio dedicada a América son algunas de las razones que ayudan a entender por qué. La información que llegaba de América estaba muy sesgada por las apreciaciones de los diplomáticos, cuyo espíritu de cuerpo y aun de clase agudizaba los prejuicios y estereotipos apuntados. Exageraba la proclividad de los medios gubernamentales americanos e infravaloraba el poder de la opinión pública democrática. El nacionalismo y el antiliberalismo compartido por casi todos no hicieron sino acentuar esos errores de percepción.

Por otra parte, la debilidad administrativa de la Sección de Ultramar no ayudó a compensar los defectos señalados. La escasez endémica de personal, los largos períodos de interinidad en su jefatura y las intromisiones constantes de otros organismos (dentro y de fuera del Palacio de Santa Cruz) impidieron que la Sección (más tarde Dirección General) se erigiese en el organismo transmisor de una cierta continuidad burocrática en la gestión diplomática y pudiese mantener bien informados a los representantes en América. Mientras en el servicio exterior norteamericano los representantes acreditados en América Latina recibían copias hasta de los despachos que sus compañeros de área mandaban al Departamento de Estado, los representantes franquistas permanecian durante meses ignorantes de cuál era la línea política básica de Madrid.

La participación directa de Franco en la elaboración de la política americana está documentada sólo en cuestiones relacionadas con el trato a las colonias de españoles, en recomendaciones de directrices católicas y en el veto impuesto al tema de las relaciones con México. Sin embargo, es indudable que con su presencia (inmanente o telefónica) marcaba los límites de la actuación de los ministros, elegidos en la medida en que podian contribuir al mantenimiento del régimen y no tanto por los proyectos políticos personales que pudieran defender. De hecho, los cambios de rumbo que el Generalísimo imprimió al régimen entre 1939 y 1945 se reflejaron perfectamente en los vaivenes de la política hispanoamericanista: primero, el proceso de fascistización (entre 1939-41) y, después, el progresivo - pero lento - desdibujamiento del modelo totalitario por la presión militar, monárquica e internacional.

No obstante, el estallido nacionalista de junio de 1940, que vislumbró una política norteafricana de poder y otra de prestigio e influencia política en América Latina, no se puede identificar exclusivamente con el proyecto 
de Serrano Súñer. Las proclamas hispanistas más beligerantes salieron de la Asociación Cultural Hispanoamericana (nada falangista) en junio de 1940 y no suscitaron la oposición de ningún grupo político. El amago de beligerancia de junio a noviembre de 1940 tuvo mucho más impacto en América que el intento de serranista de falangistizar el aparato diplomático, porque para entonces las filiales americanas ya estaban en un estado de desintegración irreversible. Asimismo, el Consejo de la Hispanidad no pasó de su fase organizativa y no llevó a cabo ninguna iniciativa en suelo americano. Por lo que respecta a la rectificación de esa política, el comienzo del cambio - la modulación «integrista» de la diplomacia española - no se inició con Jordana, sino con el propio Serrano, desde fines de 1941; aunque Jordana diese credibilidad al nuevo rumbo político. La desfalangistización de la diplomacia que éste último emprendió tampoco supuso la conversión inmediata al realismo político, ni la renuncia a los objetivos más grandiosos de prestigio e influencia en América. El pragmatismo sólo se impuso con el tiempo, conforme se dejó sentir la condena internacional.

Respecto a los paises latinoamericanos, la relevancia que para ellos tenia el vínculo con España era mínima, sobre todo en circunstancias tan duras como las de la II Guerra Mundial. El antitotalitarismo (su versión antifalangista) tuvo utilidades muy diversas para los mandatarios latinoamericanos: como medio de acercamiento a Washington, como escusa para desarrollar mecanismos de control sobre la oposición interna, etc.. Por último, las secuelas de la Guerra Civil hicieron que la causa de la República siguiera conformando una bandera enarbolable en la vida política de algunos países como símbolo imperecedero de la lucha por la democracia. Todo ello en una coyuntura como la de 1939-45, en que la conmoción ideológica provocada por el conflicto mundial hizo que para resolver las tensiones socio-políticas vividas en muchos paises se optase por cauces antioligárquicos y democráticos.

En resumen, la «Hispanidad», como ingrediente simbólico del discurso franquista, sirvió, en primer lugar, para reforzar objetivos de política interior: en los esquemas protofascistas de la época inicial, como argumento de exaltación patriótica; más tarde, en la adaptación del régimen hacia un corporativismo católico, con la machacona palabrería sobre la umisión católica". Fue, por supuesto, un elemento de legitimación internacional, primero ante el Eje y después ante los aliados. Pero desde 1939 también se soñaba con una actuación brillante en ultramar como uno de los objetivos permanentes de la politica exterior del régimen y un aditamento básico del nacionalismo exaltado de los decisores franquistas. En este último proyecto el Nuevo Estado fracasó por completo. Los años transcurridos 
entre la Guerra Civil española y el flnal de Guerra Mundial supusieron una grave pérdida de posiciones de España en la región que iba a tardar décadas en ser restañada. 